\title{
PARAMETERIZATION OF THE ANNUAL SURFACE TEMPERATURE AND MASS BALANCE OF ANTARCTICA
}

\author{
by
}

\author{
J.P.F. Fortuin and J. Oerlemans
}

(Institute of Meteorology and Oceanography, University of Utrecht, Princetonplein 5, 3584 CC Utrecht, The Netherlands)

\section{ABSTRACT}

This study entails the parameterization, by means of a linear multiple-regression analysis, of the annual surface temperature and mass balance of Antarctica. The analysis was performed for the entire ice cap as well as for three separate regions: ice shelves (elevation less than $200 \mathrm{~m}$ ), the interior (elevation above $1500 \mathrm{~m}$ ), and the escarpment region in between. It was found that temperature can be parameterized very well in terms of elevation and latitude. The latitudinal gradient on the ice shelves can be explained by the super-adiabatic lapse rate along the surface and latitudinal temperature gradient in the interior, assuming adiabatic descent of air in the inversion layer from the interior region towards the coast and an axisymmetric spreading over the ice shelves. The surface mass balance can be parameterized reliably only in the interior, where it has a strong positive correlation with the saturation vapour pressure of the free atmosphere, and a significant correlation with the shape of the dome. The convex shape of the dome contributes to the mass balance by inducing subsidence of the relatively moist air of the free atmosphere into the inversion layer. This results in precipitation, as radiative cooling in the inversion exceeds adiabatic warming. An estimate is made of the annual horizontal and vertical advective velocities in the free atmosphere above the interior, based on regression results and a physical analysis of the precipitation processes in this region.

A temperature sensitivity analysis was performed for the current mass-balance distribution. For a $1 \mathrm{~K}$ rise in surface temperature, the regression estimate of the increase in accumulation on the grounded ice sheet is equivalent to a rate of sea-level lowering of $0.2 \mathrm{~mm} \mathrm{a}^{-1}$. This is about $30 \%$ less than estimates based on the current mass balance perturbated by the increase in saturation vapour pressure of the free atmosphere.

\section{INTRODUCTION}

The Antarctic continent is $98 \%$ covered by an ice sheet with a volume of about $30 \times 10^{6} \mathrm{~km}^{3}$. To keep this giant in shape, a net annual amount of about $2300 \mathrm{~km}^{3}$ of ice has to be deposited on its surface. About $86 \%$ of the precipitation falls on the grounded ice sheet; this would be enough to lower world sea-level by $5 \mathrm{~mm}$ per year, were it not that about the same annual amount is returned to the oceans in the form of icebergs. If, however, due to some change in meteorological conditions, this net accumulation changed, its effect on sea-level would be quite instantaneous, as the compensating iceberg response follows much later. In view of the anticipated global greenhouse warming, it seems prudent to obtain a good insight into the physical parameters that govern its distribution. Such knowledge could also be applied in ice-sheet models for paleoclimatic studies.

Research has been done, amongst others, by Muszynski and Birchfield (1985), who found essentially linear relations between surface mass balance, surface temperature and elevation. Their analysis was based on two data sets of 156 and 208 data points. The current study is based on 876 surface mass balance measurements and 927 temperature measurements at $10 \mathrm{~m}$ depth, which were projected on a surface elevation grid in order to determine the corresponding topographic parameters. The most significant parameters, selected by a linear multiple-regression analysis, were found to be elevation and latitude for the surface temperature, and surface slope, surface shape (i.e. a convex, concave or flat surface) and saturation vapour pressure of the free atmosphere for the mass balance. Distance to the nearest shore was also considered, but found to have no independent contribution, a conclusion reached also by Muszynski and Birchfield.

In an attempt to explain more detailed features of the mass-balance distribution, especially in the coastal area, two additional parameters were considered: (i) precipitation resulting when air circulating due to offshore cyclone activities is forced to rise by the terrain slope, and (ii) accumulation/abalation caused by convergence/divergence of a wind-driven snow flux. However, these two parameters did not explain a significant enough contribution to the surface mass balance to justify a further detailed description. Regression analysis was performed for the entire ice sheet, as well as for three separate regions: ice shelves (elevation less than $200 \mathrm{~m}$ ), interior (elevation above $1500 \mathrm{~m})$, and the escarpment region in between. Other aspects studied are the temperature sensitivity of the mass-balance distribution and its consequences for world sea-level, as well as a physical interpretation of the regression results.

\section{METHOD OF PARAMETERIZATION}

\section{Data sets}

The parameterization was based on three digitized data sets: 876 annual surface mass-balance measurements (Fig. 1) and 927 temperature measurements at $10 \mathrm{~m}$ depth (Fig. 2), both compiled at the Scott Polar Research Institute in Cambridge, as well as a $20 \mathrm{~km}$ by $20 \mathrm{~km}$ surface elevation grid, which is a digitization of the map compiled by Drewry and others, (1984), performed at the University of Melbourne. Studies have shown that the temperature at $10 \mathrm{~m}$ depth is very closely related to the annual surface temperature, as at this depth the seasonal surface temperature variation is approximately filtered out. To determine the influence of surface temperature on mass balance, the temperature and mass-balance measuring sites which were in close proximity to each other were grouped together, resulting in a smaller data set of 486 combined measurements. To obtain the topographic parameters corresponding with the measuring sites, these data sets were projected on the surface elevation grid. On the resulting expanded data sets, consisting of the measuring site locations and their corresponding meteorological and topographic parameters, a linear multiple regression analysis was performed. The multiple regression is based on a weighted least-squares approximation. The weighting assigned to each site is proportional to the area represented by the site, which was determined by subdividing the continent into 


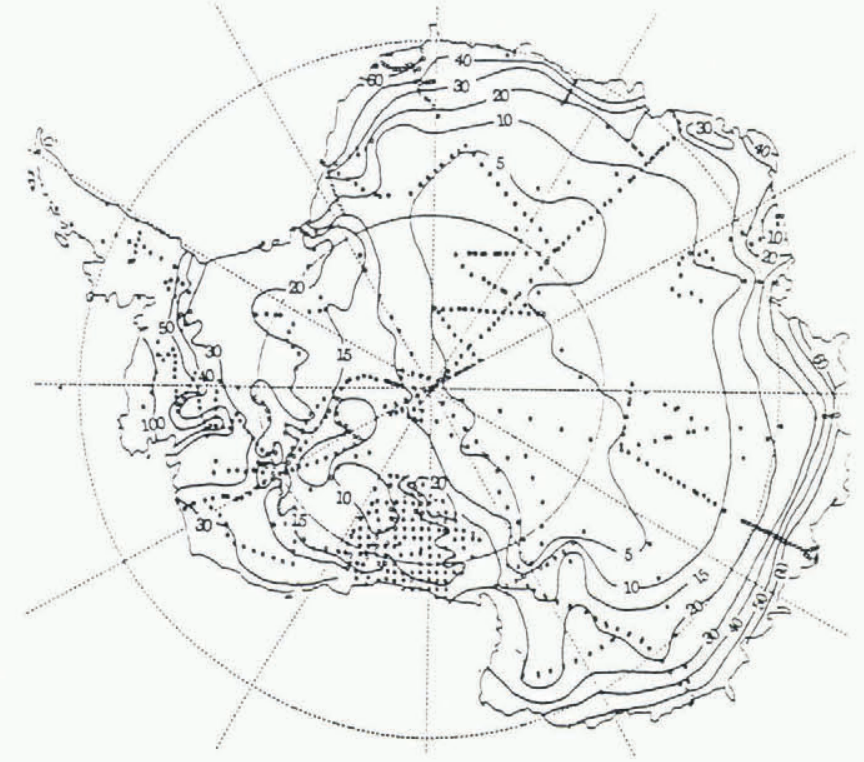

Fig. 1. Surface mass-balance measuring sites, compiled by the Scott Polar Research Institute. Isopleths from Giovinetto and Bull (1987) in $\mathrm{g} \mathrm{cm}^{-2} \mathrm{a}^{-1}$.

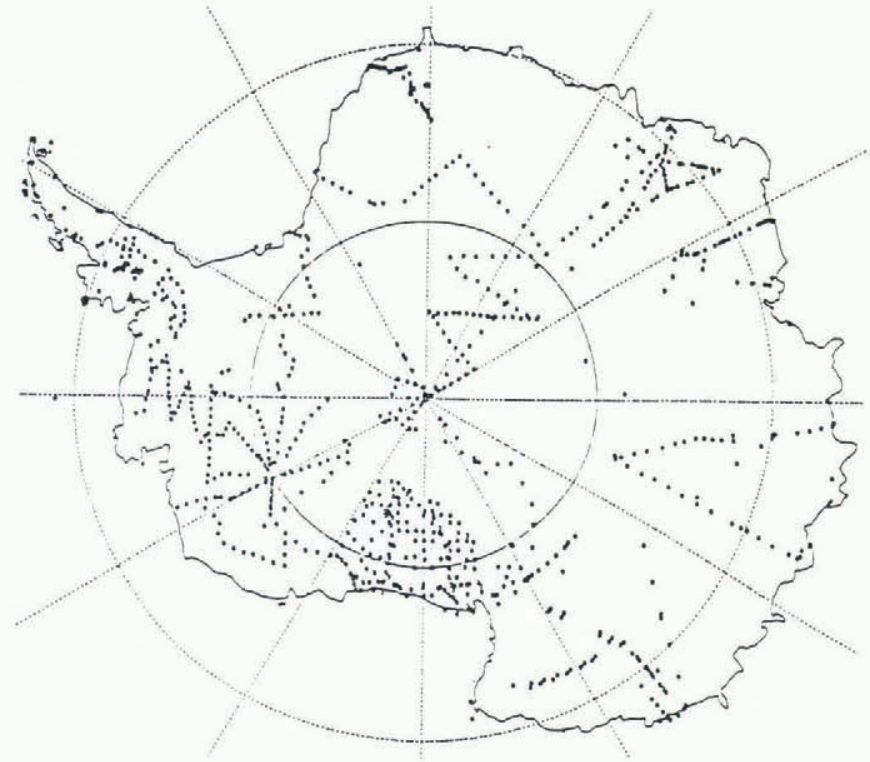

Fig. 2. $10 \mathrm{~m}$ temperature measuring sites, compiled by the Scott Polar Research Institute.

$200 \mathrm{~m}$ elevation intervals and dividing the area of the interval by the number of stations within it. This weighting was found to be unnecessary for the $10 \mathrm{~m}$ temperature measurements as it did not alter the results significantly. The analysis was performed for the entire ice sheet as well as for the three regions listed in Table I (see also Fig. 3). The reason for considering these regions separately is three-fold: (i) to separate the grounded ice sheet from the ice shelves on which changes in surface mass balance have no effect on sea-level (assuming the grounding line of the ice shelves to be at an average elevation of $200 \mathrm{~m}$ ); (ii) to

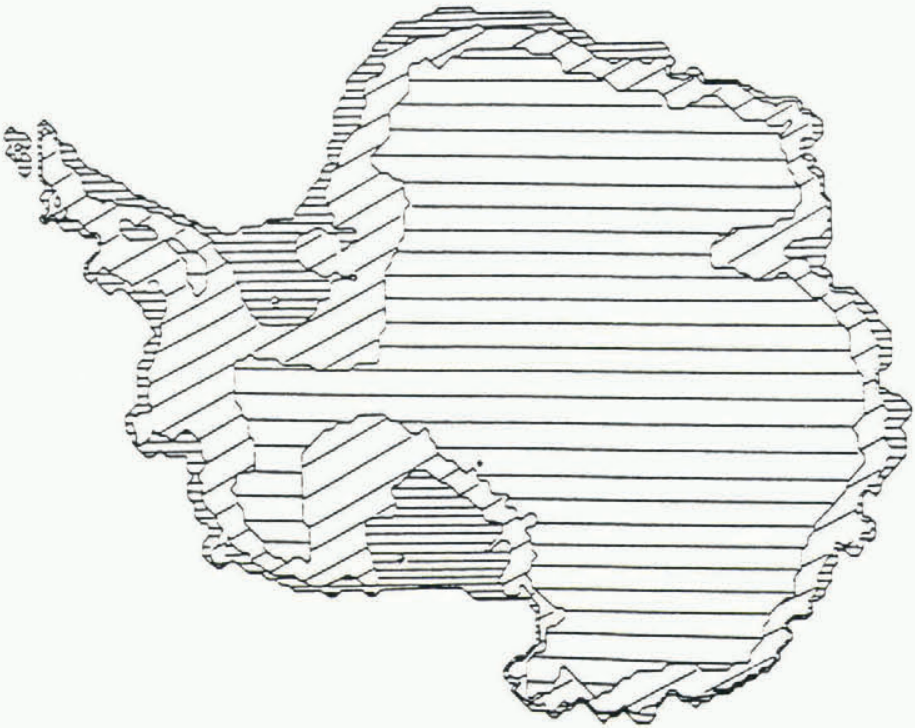

Fig. 3. Elevation intervals on which the linear multipleregression analysis is performed: ice shelves region $(0-200 \mathrm{~m})$, escarpment region $(200-1500 \mathrm{~m})$ and the interior region (above $1500 \mathrm{~m}$ ).

isolate the escarpment zone, where topographic errors are most likely to occur due to the projection of the measuring sites on a steep slope, and where relatively few surface mass-balance measurements were made in an environment with a high natural variability; and (iii) because the surface mass balance has a non-linear relation with elevation.

\section{Selection of parameters}

The parameters (which ideally have a high correlation with the dependent variable and no correlation with each other), considered for the surface temperature parameterization were: surface elevation, in $\mathrm{km}$ (further denoted as $E 1$ ); latitude, in degrees South (denoted by $L a$ ); continentality, or distance to the nearest ice-free shore, in $\mathrm{km}$.

Additional predictors selected for the mass-balance parameterization the way they were calculated, as well as their physical relevance, will now be discussed briefly.

Surface slope, in $\mathrm{m} \mathrm{km}^{-1}$ (denoted by Sl). This value was determined by a linear interpolation of the elevation values within the square grid on which the site was projected. The surface slope influences the mass balance by forcing the poleward-flowing, relatively moist air above the inversion to rise (or enter the inversion layer), resulting in precipitation.

Surface shape, in $\mathrm{m} \mathrm{km}^{-2}$ (denoted by $D$ s). This value was computed by determining the divergence of the surface slope over the square grid in which the measuring site was projected. Its contribution to the mass balance in the interior region, where the surface is predominantly convex, can result from diverging flow enforced within the inversion layer, which again induces downward advection of the relatively moist layer above. As radiative cooling within the inversion exceeds downward adiabatic warming, this can result in the forming of hoar frost or rime on the surface. This interpretation is supported by the regression results and by the lapse rate between 500 and 300 mbar, which shows a minimum above the dome, indicating

TABLE I. SUB-DIVISION OF THE ANTARCTIC CONTINENT INTO THREE ELEVATION INTERVAL REGIONS, FOR STATISTICAL ANALYSIS PURPOSES. (Mb IS MASS BALANCE, TS SURFACE TEMPERATURE)

$\begin{array}{lclcc}\text { Region } & \text { Elevation range } & \text { Area } & \text { Mean Mb } & \text { Mean Ts } \\ & \mathrm{m} & \mathrm{km}^{2} & \mathrm{~g} \mathrm{~cm}^{-2} \mathrm{a}^{-1} & { }^{\circ} \mathrm{C} \\ \text { 1. Ice shelves } & 0-200 & 1623944 & 19.2 & -24.3 \\ \text { 2. Escarpment } & 200-1500 & 3703242 & 30.0 & -23.1 \\ \text { 3. Interior } & 1500-4000 & 8592406 & 10.2 & -45.3\end{array}$


TABLE II. LINEAR MULTIPLE-REGRESSION RESULTS IN THE FORM: TS = A.E 1 + B.La + C, WITH Ts $=$ SURFACE TEMPERATURE $\left({ }^{\circ} \mathrm{C}\right), \quad$ El $=$ ELEVATION $(\mathrm{km}), \quad$ AND La $=$ LATITUDE (DEGREES SOUTH). LISTED ARE, FOR THE VARIOUS REGIONS, THE COEFFICIENT VALUES AND THEIR 95\% CONFIDENCE INTERVALS, THE PERCENTAGE VARIANCE EXPLAINED BY THE REGRESSION MODEL $(\% V)$, AS WELL AS THE STANDARD DEVIATION OF THE RESIDUALS

$(\sigma)$

\begin{tabular}{|c|c|c|c|c|c|c|c|}
\hline \multirow[t]{2}{*}{ Region } & \multicolumn{4}{|c|}{ Regression coefficients } & \multicolumn{2}{|r|}{$\% V$} & $\sigma$ \\
\hline & A & & B & & $\mathrm{C}$ & & ${ }^{\circ} \mathrm{C}$ \\
\hline Antarctica & $-9.140 \pm 0.343$ & -0.688 & \pm 0.064 & 34.461 & \pm 4.796 & 81.4 & 5.8 \\
\hline Ice shelves & 0.0 & -0.943 & \pm 0.090 & 49.642 & \pm 7.056 & 82.0 & 2.2 \\
\hline Escarpment & $-5.102 \pm 1.457$ & -0.725 & \pm 0.117 & 36.689 & \pm 9.142 & 59.3 & 3.5 \\
\hline Interior & $-14.285 \pm 0.645$ & -0.180 & \pm 0.070 & 7.405 & \pm 4.905 & 85.0 & 3.9 \\
\hline
\end{tabular}

increased downward advection (Schwerdtfeger, 1984). However, in the escarpment region, where wind velocities are high enough to transport surface snow, a convex surface would cause a diverging drfiting-snow flux, which could result in a net ablation instead. This parameter was set to zero for concave surfaces as no similar argument holds to explain its influence on the mass balance (also found to have no correlation).

Saturation vapour pressure of the free atmosphere above the inversion, in mbar (denoted by Es). Jouzel and Merlivat (1984) found that the annual mean temperature of this layer (denoted as $T f$ ), which constitutes the warmest part of a vertical profile, has a spatial linear relation (correlation 0.99) with the annual surface temperature $(T S)$. They proposed an empirical relation based on annual mean data collected from measurements all over the continent:

$$
T f[\mathrm{~K}]=0.67 T s[\mathrm{~K}]+88.9
$$

The saturation vapour pressure over ice was then calculated for this temperature using the Clausius Clapeyron equation. Its physical significance on the surface mass-balance distribution is that it sets an upper limit to the amount of vapour available for precipitation. This argument was first suggested by Robin (1977), who found the relation of the free atmosphere temperature with accumulation to be similar to the Clausius Clapeyron relation.

\section{RESULTS}

\section{Linear regression}

The equations resulting from the linear multipleregression analysis are listed in Tables II and III, together with the percentage variance explained by each equation (the higher the better), and the standard deviation $(\sigma)$ of the residuals (the smaller the better). Table IV lists the corresponding correlations of the predictors with the dependent variables, as well as the percentage contribution of the average predictor value to the annual mean mass balance of the various regions.

When applying the regression results to the gridded surface elevation, the temperature and mass-balance distributions shown in Figures 4 and 5 are obtained. To prevent discontinuities at the borders of the three elevation intervals, a linear interpolation (based on elevation) was performed on the coefficients between 200 and $400 \mathrm{~m}$, and between 1300 and $1500 \mathrm{~m}$. Regarding the high percentage of variance explained by the temperature parameterization, the distribution shown in Figure 4 can be considered as quite accurate. As for the mass-balance distribution, a comparison of Figure 5 with Figure 1 suggests a reasonable agreement for the interior and ice-shelf regions. Clearly, this does not apply for the escarpment region, as the regression results here are quite insignificant.

Temperature sensitivity

As the saturation vapour-pressure parameter is by far

TABLE III. REGRESSION RESULTS OF THE FORM: Mb = A.Es + B.SI + C.Ds + D, WITH $\mathrm{Mb}=$ SURFACE MASS BALANCE $\left(\mathrm{cm} \mathrm{a}^{-1}\right)$, Es = SATURATION VAPOUR PRESSURE OF THE FREE ATMOSPHERE $(\mathrm{m}$ bar $), \mathrm{Sl}=$ SURFACE SLOPE $\left(\mathrm{m} \mathrm{km}^{-1}\right)$, Ds = SURFACE SHAPE $\left(\mathrm{m} \mathrm{km}^{-2}\right)$. LISTED ARE, FOR THE VARIOUS REGIONS, THE COEFFICIENT VALUES AND THEIR $95 \%$ CONFIDENCE INTERVALS, THE PERCENTAGE VARIANCE EXPLAINED BY THE REGRESSION MODEL $(\% V)$, AND THE STANDARD DEVIATION OF THE RESIDUALS $(\sigma)$

Region

A

$\begin{array}{lrll}\text { Antarctica } & 13.050 \pm 2.735 & 0.664 \pm 0.510 \\ & & & \\ \text { Ice shelves } & 23.503 & \pm 6.507 & 0.0 \\ \text { Escarpment } & 5.732 \pm 8.236 & 1.437 \pm 1.028 \\ \text { Interior } & 21.024 \pm 2.787 & 0.0\end{array}$

Regression coefficients

$\mathrm{C}$

$-15.276 \pm 11.91$

D

$\% V$

$\mathrm{cm} \mathrm{a}^{-1}$ 
TABLE IV. CORRELATIONS OF THE PREDICTORS WITH SURFACE TEMPERATURE AND MASS BALANCE. PERCENTAGE CONTRIBUTION OF THE AVERAGE PREDICTOR VALUE TO THE ANNUAL MASS BALANCE IS GIVEN IN BRACKETS

Dependent variable

Predictor

Ts

E1

La

Es

S1

Ds

$\begin{array}{lc} & \text { Antarctic } \\ \text { E1 } & -0.85 \\ \text { La } & -0.52 \\ \text { Es } & 0.61(64) \\ \text { S1 } & 0.44(15) \\ \text { Ds } & -0.36(4)\end{array}$

Correlation coefficient

$\begin{array}{ccc}1 & 2 & 3 \\ \mathrm{x} & -0.33 & -0.92 \\ -0.91 & -0.66 & -0.52 \\ & & \\ \mathrm{x}(171) & 0.34(31) & 0.81(85) \\ \mathrm{x} & 0.22(34) & \mathrm{x} \\ \mathrm{x} & \mathrm{x} & -0.69(15)\end{array}$

the most important parameter in determining the distribution of the surface mass balance, particularly for the interior region, it seems reasonable to use the results to attempt an estimate of the change in mass balance in response to an imposed temperature perturbation. The increase in accumulation due to a $1 \mathrm{~K}$ rise in annual surface temperature was calculated and compared with two other methods. These two methods are based on the current measured surface mass balance perturbed by: (i) the ratio of change of the temperature derivative of the saturation vapour pressure, (ii) the ratio of change of the saturation vapour pressure. The first method was used also by Lorius and others (1985) in order to re-establish a time-scale, independent of other paleoindicators, for interpreting the Vostok ice core. The accumulation rates calculated in this way were found to be consistent with ${ }^{10} \mathrm{Be}$ concentrations. The resulting increase in accumulation for the respective areas, due to the $1 \mathrm{~K}$ increase in surface temperature, are listed in Table V. Apparently, for the interior region, the regression equation yields a slightly lower increase than the other two estimates. For the escarpment region the uncertainty of the estimate becomes very large (the uncertainty is derived from the confidence interval assigned to each coefficient by the statistical programme). However, the increase in accumulation obtained from the regression equation for the entire ice cap (first equation of Table III), is about the same for the grounded ice-sheet area as the sum of the predicted values for the interior and escarpment region. The reason why this is significantly less than the other two estimates must be due to the temperatureindependent contribution of the topographic parameters included in the regression equations. The coresponding rates of sea-level lowering of the regression and two other estimates are $0.20,0.31$, and $0.34 \mathrm{~mm} \mathrm{a}^{-1}$, respectively.

An estimate was also made of the surface massbalance change that occurred during the last glacial maximum, and compared with analysed values of ice cores drilled at Vostok, Dome C, and Byrd Stations (Lorius and others, 1984). These core analyses are based on the perturbation method (i) mentioned above, as well as ${ }^{10} \mathrm{Be}$ concentrations. Although the absolute values of the interior regression estimates did not agree so much with those of the core analyses (partly due to the uncertainty of the location of the source region during the LGM), it did more or less calculate the proper change ratios, which, in the same following order of the three stations listed above, are $0.67,0.62$, and 0.51 of the current surface mass-balance values due to a corresponding temperature lowering (based on $8^{18} \mathrm{O}$ values) of $8^{\circ}, 9^{\circ}$ and $10^{\circ} \mathrm{C}$, respectively (the core analyses ratio estimates are $0.60,0.60$, and 0.40 , respectively). It must be noted that these regression calculations rest on the two important assumptions that during the LGM the surface shape and relative humidity of the free atmosphere were similar to current conditions. This is probably not a bad estimation for the interior region (Lorius and others, 1984), but little attention should be paid to the regions below that.

\section{DISCUSSION}

\section{Surface-temperature parameterization}

Since the regression analysis of the annual surface temperature yielded good results, an attempt can now be made to explain the obtained regression coefficients in terms of physical processes. The lapse rate along the surface (meaning the change of surface temperature with elevation as one moves up the ice-sheet slope) was found to be super-adiabatic $\left(-14.3 \mathrm{deg} \mathrm{km}^{-1}\right)$ for the interior region. This can be explained by the intense radiative cooling, which is very effective at these low temperatures as the atmosphere is almost transparent to the emitted wavelengths (except for the $\mathrm{CO}_{2}$ absorption band between 13 and $15 \mu \mathrm{m}$, corresponding to the maximum intensity of radiation for a black body at $-50^{\circ}$ to $-60^{\circ} \mathrm{C}$ ). In adition, the emissivity of the atmosphere is further reduced by about the square root of the atmospheric pressure. In summer time no effective warming can occur due to the small solar elevation as well as the high albedo of the snow surface. Therefore, the air in the inversion layer is on average negatively buoyant with

TABLE V. ACCUMULATION ( $\mathrm{kg}^{3}$ WATER) AND ITS INCREASE DUE TO A $1 \mathrm{~K}$ RISE IN ANNUAL SURFACE TEMPERATURE FOR THE GROUNDED ICE SHEET AND THE THREE ELEVATION INTERVALS

Region $\begin{gathered}\text { Current mass } \\ \text { supply }\end{gathered}$

$\mathrm{kg}^{3}$
Ice sheet

1816.9
Calculated mass increase due to $1 \mathrm{~K}$ rise in $\mathrm{Ts}$ regression $\quad \partial e_{\mathrm{S}} / \partial T$ ratio $e_{\mathrm{S}}$ ratio
Interior

879.5

Escarpment

937.4

286.9
$72.8 \pm 15.3$

112.6

121.7

$21.1 \pm 30.3$ 
respect to the free atmosphere and will descend over a sloping surface, warming adiabatically until it reaches a level of the same surrounding density. When constructing a lapse-rate diagram based on the regression coefficients of the interior and escarpment region, it is clear that air descending from the high interior will continue to flow all the way down to the ice shelves, where it will spread out. Air originating in the escarpment region with its stable sub-adiabatic surface lapse rate will however be stagnant. It therefore seems possible that the latitudinal temperature gradient observed on the ice shelves can be explained by the combined lapse rate and latitudinal gradient of the high interior region, when warmed adiabatically on its descent. This is confirmed by the following theoretical consideration. Mass continuity and maintenance of the difference in potential virtual temperature between the top and bottom of a descending slab of air (see derivation in Appendix B), yields the equation:

$$
\left[\gamma_{\mathrm{v}}^{\prime}-\gamma_{\mathrm{d}}\right] \phi^{\prime}+\frac{\partial T_{\mathrm{v}}^{\prime}}{\partial x^{\prime}}=\frac{P^{\prime} h^{\prime}}{P h}\left[\left(\gamma_{\mathrm{v}}-\gamma_{\mathrm{d}}\right) \phi+\frac{\partial T_{\mathrm{v}}}{\partial x}\right]
$$

where the prime refers to the region of destination (ice shelves). Variables without prime designate the characteristics of the air in the source region (interior). The average surface slope is denoted by $\phi$ (equal to $S l$ in the regression analysis, which for the ice shelves is about zero), $h$ indicates the height of the inversion layer per unit width, $P$ the average atmospheric pressure, $\gamma_{\mathrm{v}}$ and $\gamma_{\mathrm{d}}$ the lapse rate along the surface and dry adiabatic lapse rate respectively, and $\partial T_{\mathrm{v}} / \partial x$ the horizontal (in this case latitudinal) temperature gradient. After substitution of the interior regression coefficients in Equation (2), the latitudinal gradient of the ice shelves is obtained if $h^{\prime}=h / 2$. This means that in addition to adiabatic warming, diverging flow must occur (i.e. lowering of the inversion height) during the descent, which seems quite reasonable. This argument could be used then also to explain the stable sub-adiabatic lapse rate of the escarpment region $\left(-5 \mathrm{deg} \mathrm{km}{ }^{-1}\right)$, as ineffective drainage of the interior-derived air on the ice shelves could lower the temperature at the bottom of the escarpment region, thus reducing the lapse rate along the surface for this region.

\section{Surface mass-balance parameterization}

A similar attempt can be made to obtain a theoretical expression explaining the regression results of the surface mass-balance parameterization for the interior region (as the regression results for the other two regions are not reliable enough). Imagine a relatively warm advective layer above the inversion with average temperature equal to that calculated by Equation (1), and in which effectively all the moisture that constitutes the precipitation is contained (Fig. A1). Further assume that the layer is saturated and that all condensing moisture immediately falls out as precipitation. The following equation (see Appendix A for a detailed derivation) essentially describes the precipitation ( $G$, in $\mathrm{mm} \mathrm{s}^{-1}$ ) resulting from moist air in this layer being advected isobarically polewards (with velocity $u$ ) over a negative latitudinal temperature gradient $\left(\partial T_{\mathrm{f}} / \partial_{x}\right.$, being the latitudinal gradient of ther free atmosphere, derived from differentiating Equation (1)) and consequently subsiding (velocity $w$ ) into the inversion layer (with lapse rate $\gamma_{\text {inv }}$ ); as well as precipitation resulting from orographically induced uplifting by the terrain slope $(\phi)$ :

$$
G=\left\{\frac{\varepsilon^{2} L_{\mathrm{s}} \Delta P}{g R_{\mathrm{d}} P}\left[\frac{\partial T}{\partial x} u+\left(\gamma_{\mathrm{d}}+\gamma_{\text {inv }}\right) w\right]\right\} \frac{e_{\mathrm{S}}}{T^{2}}-\left\{\frac{\varepsilon}{R_{\mathrm{d}}} u\right\} \frac{\phi e_{\mathrm{S}}}{T}
$$

If we now also impose mass continuity of a disk section of this advective layer (see Equation (A4)), substitute this in Equation (3), and perform a multiple-regression analysis on the resulting variables $e_{\mathrm{S}} / T^{3}$ and $\phi e_{\mathrm{S}} / T$ (see Equation (A6)), the annual mean horizontal poleward - and vertical subsidence - velocities above the interior region can be obtained:

$$
\begin{aligned}
w & =-2.5 \mathrm{~mm} \mathrm{~s}^{-1} \\
u & =-0.29 \mathrm{~m} \mathrm{~s}^{-1}
\end{aligned}
$$

These values are quite in agreement with other estimates in the literature. However, as it is based on a wide range of assumptions, it should only be seen as an indication of the order of magnitude of these advective processes. It also indicates what assumptions are made when using a constant coefficient for the Es parameter (i.e. marine aerosol concentrations in ice cores indicate around 1.2 to 2 times higher advective velocities during the LGM, which, together with the temperature lowering, should result in a bigger value for this coefficient). Note however that the slope divergence term $(D s)$, which was not taken into account in this analysis (it would require knowledge of the accompanying diverging inversion layer flux), would add to the calculated subsidence rate. The $D s$ parameter contributes on average about $15 \%$ to the annual mass-balance value of the interior, and becomes particularly significant at the top of the dome where the Es parameter is very low. The interesting consequence of this argument is that the very shape of the dome seems to be an important element in maintaining and building up its own structure.

\section{CONCLUSIONS}

The most obvious conclusion from this study is that the annual surface temperature can be parameterized very well in terms of elevation and latitude. The lapse rate along the surface was found to be super-adiabatic $\left(-14 \mathrm{~K} \mathrm{~km}^{-1}\right)$ in the interior region above $1500 \mathrm{~m}$, and sub-adiabatic $\left(-5 \mathrm{~K} \mathrm{~km}^{-1}\right)$ in the coastal area. The latitudinal temperature gradient along the surface of the ice-shelf region $\left(-0.9 \mathrm{~K} \mathrm{deg}^{-1}\right)$ can be explained by the combined lapse rate and latitudinal temperature gradient $\left(-0.2 \mathrm{~K} \mathrm{deg}^{-1}\right)$ along the surface of the interior region, assuming adiabatic descent of air from the interior towards the coast and an axisymmetric spreading over the ice shelves. The accumulation of cold air at the bottom of the escarpment region adjacent to the ice shelves (due to inefficient discharge of the interior-derived air) could then explain the sub-adiabatic lapse rate of this region.

Concerning the mass balance, only the interior region above $1500 \mathrm{~m}$ can be parameterized reliably $(72 \%$ of the variance explained) in terms of the saturation vapour pressure of the free atmosphere above the inversion and the convexity of the surface, which on average contribute about 85 and $15 \%$ respectively to the annual mean mass balance of this region. The influence of the convex-shaped surface in the high interior region must be due to the diverging flow it induces in the inversion layer, causing subsidence of the relatively moist advective layer above. This results in precipitation, as radiative cooling in the inversion exceeds downward adiabatic warming. A physical analysis of the maximum precipitation rate from the free atmosphere above the interior region yielded estimates of the annual mean horizontal poleward and vertical subsidence velocities in the free atmosphere of 0.29 and $2.5 \mathrm{~mm} \mathrm{~s}^{-1}$, respectively. Reasonable results were obtained also for the ice shelves regions ( $35 \%$ of the variance explained), indicating that under current circumstances growth of the ice shelves would occur were it not for ablative processes (katabatic wind erosion?) represented in the regression equation by a negative constant. Averaged over the entire ice cap, the surface slope contribution to the annual mass balance is about $0.7 \mathrm{~g} \mathrm{~cm}^{-2} \mathrm{a}^{-1}$ for every $\mathrm{m} \mathrm{km}^{-1}$ increase in slope. In the escarpment region this value increases to $1.4 \mathrm{~g} \mathrm{~cm}^{-2} \mathrm{a}^{-1}$ per $1 \mathrm{~m} \mathrm{~km}^{-1}$ increase in slope. However, the processes governing the mass-balance distribution in the escarpment region are too complex and the amount of available measurements too small currently to justify a reliable parameterization.

Due to the strong positive temperature dependence of mass balance in the interior (on average $0.6 \mathrm{~g} \mathrm{~cm}^{-2} \mathrm{a}^{-1} \mathrm{~K}^{-1}$ ) and the long time it takes before the compensating ice calving would occur, the expected rate of sea-level increase due to global greenhouse warming might be somewhat reduced. The regression estimate of the accumulation increase on the grounded ice sheet due to a $1 \mathrm{~K}$ rise in 
annual surface temperature is equivalent to a $0.20 \mathrm{~mm} \mathrm{a}^{-1}$ rate of sea-level lowering. Of this quantity, $0.14 \mathrm{~mm}$ is quite certain as it results from a mass supply increase to the interior region. Still this is significantly less than other estimates based on the current surface mass balance perturbated by the ratio of increase of the saturation vapour pressure, which are around $0.3 \mathrm{~mm} \mathrm{a}^{-1}$ for the same temperature rise. This discrepancy must be sought in the fact that the ratio increase in accumulation, according to the regression estimate, has a constant added to the saturation vapour-pressure term (the topographic parameter influence) for both the numerator and denominator, which reduced the ratio increase relative to the two other estimation techniques, that are based on the change of the temperature-dependent terms alone. As for bigger temperature fluctuations, the regression estimate of the decrease in mass balance during the LGM is quite in agreement with analyses performed on ice cores drilled at the stations Vostok, Dome C, and Byrd. However, the effect of large positive temperature perturbations cannot be simulated by the regression model as melting is not taken into account.

\section{ACKNOWLEDGEMENTS}

We thank M. Giovinetto, P. Martinerie, and G. Wendler for providing valuable information related to this subject.

\section{REFERENCES}

Drewry, D.J., ed. 1983. Antarctica: glaciological and geophysical folio. Cambridge, University of Cambridge. Scott Polar Research Institute.

Giovinetto, M.B. and C. Bull. 1987. Summary and analyses of surface mass balance compilations for Antarctica, 1960-1985. Ohio State University. Byrd Polar Research Center. Report 1.

Jouzel, J. and L. Merlivat. 1984. Deuterium and oxygen 18 in precipitation: modeling of the isotopic effects during snow formation. J. Geophys. Res., 89(D7), 11,749-11,757.

Lorius, C., D. Raynaud, and J.-R. Petit. 1984. Late-glacial maximum - Holocene atmospheric and ice-thickness changes from Antarctic ice-core studies. Ann. Glaciol., 5, 88-94.

Lorius, C., and 6 others. 1985. A 150,000-year climatic record from Antarctic ice. Nature, 316(6029), 591-596.

Muszynski, I. and B.E. Birchfield. 1985. The dependence of Antarctic accumulation rates on surface temperature and elevation. Tellus, 37A, 204-208.

Robin, G. de Q. 1977. Ice cores and climate change. Philos. Trans. R. Soc. London, Ser. B, 280, 143-168.

Schwerdtfeger, W. 1984. Weather and climate of the Antarctic. Amsterdam, etc., Elsevier. (Developments in Atmospheric Science 15.)

APPENDIX A. Physical analysis of the mass-balance parameterization in the interior region

When one assumes that virtually all the precipitation in the interior region (above $1500 \mathrm{~m}$ ) is derived from saturated, relatively warm advective layer above the inversion (Fig. Al), and that all condensing moisture in this layer immediately falls out as precipitation, then the incremental mass per unit area $\left(d m_{\mathrm{p}}\right)$ falling from a column of thickness $\Delta z$ and width $d x$ will be equal to the decrease in moisture of this column $\left(d m_{\mathrm{v}}\right)$ :

$$
\begin{aligned}
d m_{\mathrm{p}} & =d m_{\mathrm{v}}=-d\left(\rho_{\mathrm{v}} \Delta z\right) \\
& =-\Delta z d \rho_{\mathrm{v}}-\rho_{\mathrm{v}} d\left(z_{\text {top }}-z_{\text {bot }}\right)
\end{aligned}
$$

with $\rho_{\mathrm{y}}$ indicating the moisture density.

The $z$-axis points upward and is located at the South Pole whereas the $x$-axis is axisymmetric and points equatorwards. Further assume that the elevation of the top of this advective layer $\left(z_{\text {top }}\right)$ stays about constant, whereas the bottom elevation is imposed by the inversion layer which

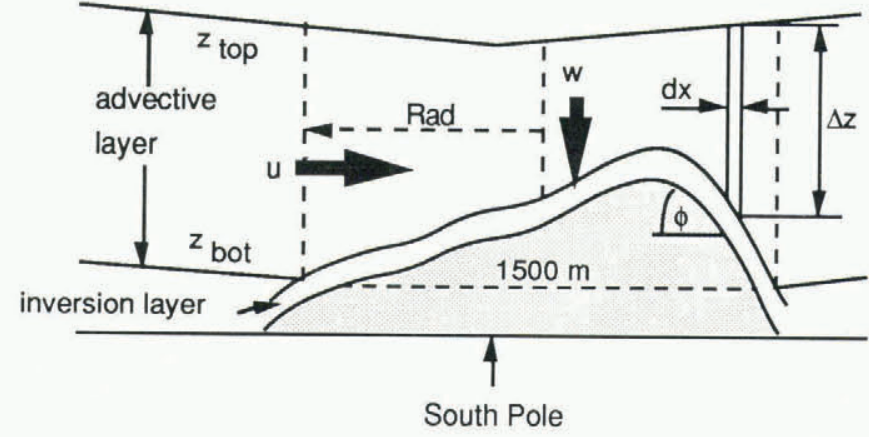

Fig. A1. Schematic cross-section of the Antarctic ice sheet covered in the interior region by an inversion and advective layer.

again follows the terrain shape (with slope $\phi$ ). This, together with the hydrostatic equation of state of an ideal gas yields:

$$
\begin{aligned}
d m_{\mathrm{p}} & =\frac{\Delta P \mathrm{~d} \rho_{\mathrm{v}}}{g \bar{\rho}}-\frac{\varepsilon \bar{e}_{\mathrm{S}}}{R_{\mathrm{d}} \bar{T}} \phi \mathrm{d} x \\
& =\frac{\Delta P \varepsilon \mathrm{d} \rho_{\mathrm{S}}}{g \bar{P}}-\frac{\varepsilon \bar{e}_{\mathrm{S}}}{R_{\mathrm{d}} T} \phi \mathrm{d} x \\
& =\frac{\varepsilon \Delta P}{g \bar{P}} \frac{\partial e_{\mathrm{S}}}{\partial T}\left\{\frac{\partial T}{\partial x} \mathrm{~d} x+\frac{\partial T}{\partial z} \mathrm{~d} z\right]-\frac{\varepsilon \overline{e_{\mathrm{S}}}}{R_{\mathrm{d}} \bar{T}} \phi \mathrm{d} x
\end{aligned}
$$

with the overbar variables indicating the averages integrated over the depth of the column. Note that an isothermal assumption has been made (going from the first to the second equality of Equation (A2)), which is reasonable since the change in temperature term is about 30 times smaller than the change in saturation vapour pressure term. Equating the precipitation $\left(G\right.$, in $\mathrm{mm} \mathrm{s}^{-1}$ ) equal to the time derivative of Equation (A2), and substituting the Clausius Clapeyron equation results in:

$$
G=\left\{\frac{\varepsilon^{2} L_{\mathrm{s}} \Delta P}{g R_{\mathrm{d}} P}\left[\frac{\partial T}{\partial x} u+\left[\gamma_{\mathrm{d}}+\gamma_{\text {inv }}\right] w\right]\right\} \frac{e_{\mathrm{S}}}{T^{2}}-\left\{\frac{\varepsilon}{R_{\mathrm{d}}} u\right\} \frac{\phi e_{\mathrm{S}}}{\bar{T}}
$$

where $u$ and $w$ are the horizontal and vertical advective values. The latitudinal temperature gradient of the free atmosphere $(\partial T / \partial x)$ is derived from the latitudinal temperature gradient along the surface from the regression results (differentiating Equation (1) with respect to $x$ ). The annual lapse rate in the inversion layer $\left(\gamma_{\text {inv }}\right)$ is also derived from Equation (1), assuming a constant inversion height of $1 \mathrm{~km}$. As adiabatic warming occurs during descent, the dry adiabate has to be added to the lapse rate in the inversion layer to determine the effective cooling rate. If one approximates the advective layer above the interior by a disk-shaped sector (radius $\mathrm{Rad}=1654 \mathrm{~km}$, which corresponds with the area occupied by the interior, as listed in Table I), mass continuity then requires:

$$
2 \pi \operatorname{Rad} \Delta z u=\pi \operatorname{Rad}^{2} w
$$

which, together with the hydrostatic equation and equation of state of an ideal gas yields:

$$
\Delta P=-\frac{g \bar{P} \mathrm{Rad}}{2 R_{\mathrm{d}} T} \frac{w}{u} .
$$


Substituting this in Equation (A3) results in the final expression:

$$
\begin{aligned}
& G=\left\{\frac{-\varepsilon^{2} L_{\mathrm{s}} \operatorname{Rad}}{2 R_{\mathrm{d}}^{2}}\left[\frac{\partial T_{\mathrm{f}}}{\partial x} w+\left[\gamma_{\mathrm{d}}+\gamma_{\text {inv }}\right] \frac{w^{2}}{u}\right]\right\} \frac{e_{\mathrm{s}}}{\frac{\overrightarrow{3}}{T}}- \\
& -\left\{\frac{\varepsilon}{R_{\mathrm{d}}} u\right\} \frac{\phi e_{\mathrm{s}}}{\bar{T}} .
\end{aligned}
$$

\section{APPENDIX B. Physical analysis of the surface-temperature parameterization of Antarctica}

Figure A2 depicts a section of the ice sheet extending from the high interior down to an ice shelf. The two slabs on top represent sample sections of the negative buoyant inversion layer of the interior, descending adiabatically and eventually spreading over the ice shelf.

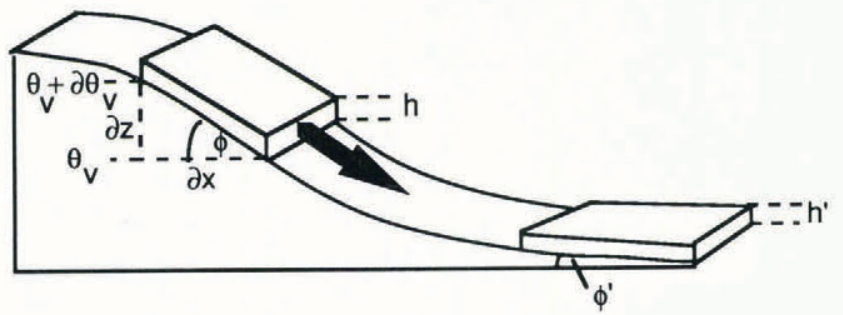

Fig. A2. Section of the ice sheet on which a sample of negatively buoyant inversion air descends and spreads out over an ice shelf.

Mass continuity of the descending slab of inversion air requires:

$$
\frac{\rho h \partial z}{\sin \phi}=\frac{\rho^{\prime} h^{\prime} \partial z^{\prime}}{\sin \phi^{\prime}} .
$$

The variables with a prime refer to the region of destination (ice shelves), whereas those without a prime designate the source region characteristics (interior). Making a small angle approximation for the surface slope $(\phi)$,
Equation (A7) can be rewritten, together with Poisson's equation

$$
\begin{aligned}
& \frac{\partial z}{\partial z^{\prime}}=\left(\frac{P^{\prime}}{P}\right)^{1-\boldsymbol{k}} \frac{\phi h^{\prime}}{\phi^{\prime} h} \\
& \frac{\partial z}{\partial x^{\prime}}=\left[\frac{P^{\prime}}{P}\right)^{1-\boldsymbol{k}} \frac{h^{\prime} \phi}{h} .
\end{aligned}
$$

Also the difference in virtual potential temperature $\left(\partial \theta_{v}\right)$ between the front and end of the descending slab must stay the same:

$$
\begin{aligned}
\partial \theta_{\mathrm{v}} & =\frac{\partial \theta_{\mathrm{v}}}{\partial z} \partial z+\frac{\partial \theta_{\mathrm{v}}}{\partial x} \partial x \\
& =\frac{\partial \theta_{\mathrm{v}}^{\prime}}{\partial z^{\prime}} \partial z^{\prime}+\frac{\partial \theta_{\mathrm{v}}^{\prime}}{\partial x^{\prime}} \partial x^{\prime} \\
& =\partial \theta_{\mathrm{v}}{ }^{\prime} .
\end{aligned}
$$

Performing respectively a logarithmic differentiation with respect to elevation $(z)$ and a direct differentiation with respect to latitude $(x)$ on the Poisson equation leads to the following two equations:

$$
\begin{aligned}
& \frac{\partial \theta_{\mathrm{v}}}{\partial z}=\left[\frac{P_{0}}{P}\right]^{\mathrm{k}}\left(\gamma_{\mathrm{v}}-\gamma_{\mathrm{d}}\right) \\
& \frac{\partial \theta_{\mathrm{v}}}{\partial x}=\left[\frac{P_{0}}{P}\right]^{\kappa} \frac{\partial T_{\mathrm{v}}}{\partial x} .
\end{aligned}
$$

Substituting Equation (A8) and (A10) into Equation (A9) then yields:

$$
\left[\gamma_{\mathrm{v}}^{\prime}-\gamma_{\mathrm{d}}\right] \phi^{\prime}+\frac{\partial T_{\mathrm{v}}^{\prime}}{\partial x^{\prime}}=\frac{P^{\prime} h^{\prime}}{P h}\left[\left(\gamma_{\mathrm{v}}-\gamma_{\mathrm{d}}\right) \phi+\frac{\partial T_{\mathrm{v}}}{\partial x}\right] .
$$

The latitudinal temperature gradient and lapse rate along the surface obtained from the regression results are then assumed equal to the horizontal and vertical derivative of the virtual temperature. 